Centre Cardio-

Pneumologique, Unité d'hémodynamique et

de Cardiologie

interventionnelle,

CHU Pontchaillou,

Rue Henri Le

Guilloux, 35033 Rennes

cedex, France

$\mathrm{H}$ Le Breton

$C$ Leclercq

M Bedossa

Centre Hospitalier

Universitaire la Cavale

Blanche, Brest

J Boschat

M Gilard

Clinique St Martin,

Caen

P Commeau

B Huret

Nouvelles Cliniques

Nantaises-St Henri,

Nantes

P Brunel

Clinique du Grand

Large, Brest

C Breut

Clinique St Gatien,

Tours

O Bar

Centre Hospitalier

Universitaire, Angers

P Geslin

Centre Hospitalier

Universitaire, Nantes

A Tirouvanziam

Centre Hospitalier

Universitaire, Tours

L Maillard

Clinique de la Reine

Blanche, Orléans

B Moquet

Centre Hospitalier

Beauregard, Marseille

P Barragan

Centre Hospitalier

Universitaire Henri

Mondor AP-HP,

Creteil

P Dupouy

Centre Hospitalier

Universitaire, Caen

G Grollier

Clinique St Hilaire,

Rouen

J Berland

Clinique St Laurent, Rennes

P Druelles

Centre Hospitalier St

Philibert, Lomme

R Rihani

Correspondence to:

Professor Le Breton

herve.lebreton@chu-rennes.fr

Accepted 15 May 2001

\title{
Randomised comparison of coronary stenting with and without balloon predilatation in selected patients
}

\author{
H Le Breton, J Boschat, P Commeau, P Brunel, M Gilard, C Breut, O Bar, P Geslin, \\ A Tirouvanziam, L Maillard, B Moquet, P Barragan, P Dupouy, G Grollier, J Berland, \\ P Druelles, R Rihani, B Huret, C Leclercq, M Bedossa, for the Stent Without Balloon \\ Predilation (SWIBAP) Study Group
}

\begin{abstract}
Background-The SWIBAP (stent without balloon predilatation) prospective randomised trial was designed to compare direct coronary stenting with stenting preceded by lesion predilatation with an angioplasty balloon.

Objective-To determine the feasibility and safety of direct stenting in non-complex coronary lesions in a prospective study.

Patients and design-All patients $<76$ years of age scheduled to undergo angioplasty of a noncomplex, non-calcified lesion in a coronary artery of $>3.0 \mathrm{~mm}$, who granted their informed consent, were randomised into the trial. In group I, the stent was placed without balloon predilatation, while in group II stent implantation was preceded by balloon predilatation. The primary end point was the angiographic result according to procedure assigned by randomisation. An intravascular ultrasound substudy was performed in 60 patients.

Results-Stent implantation was successful without predilatation in 192 of the 197 group I patients $(97.5 \%)$, and with predilatation in 197 of the 199 group II patients (99\%) (NS). No in-hospital stent thrombosis or death occurred. Overall procedural times, fluoroscopy times, and volumes of contrast agent given (mean (SD)) in group I $v$ group II were 23.50 (13.54) $\min v$ $27.96(15.23) \min (\mathrm{p}=0.002), 6.04(4.13) \min v 6.67$ (3.65) $\min (\mathrm{NS})$, and $135(65) \mathrm{ml} v 157$ (62) $\mathrm{ml}(\mathrm{p}<0.001)$, respectively. No major adverse cardiovascular events had occurred by 30 days.

Conclusions-The feasibility and safety of direct stenting of selected and non-complex coronary lesions is confirmed. This technique was as successful as the conventional approach and was associated with a minor reduction in fluoroscopic exposure and procedure time and the administration of less contrast agent.

(Heart 2001;86:302-308)
\end{abstract}

Keywords: coronary artery angioplasty; stent; coronary artery ultrasound

Percutaneous coronary angioplasty is a well established method of revascularisation, performed at an annual rate of 800000 procedures in the USA and 350000 in Europe. Balloon coronary angioplasty is currently supplemented by placement of a stent in $\geqslant 70 \%$ of cases. Several investigators have reported high success and low complication rates in coronary stenting procedures without previous balloon dilatation (direct stenting). ${ }^{1-7}$ This simplified implantation technique has several potential advantages, including shortening the procedure and fluoroscopy times, reduced amounts of contrast agent, and the use of fewer balloons. Direct stenting may also decrease the risk of no reflow and reduce the rate of restenosis at six months because of reduced trauma to the vessel wall.

The SWIBAP (stent without balloon predilatation) prospective randomised trial was designed to compare, in a large patient population, the results of direct stenting of noncomplex lesions with the standard approach, which includes balloon predilatation. A subgroup of patients underwent intravascular ultrasound in addition to clinical and angiographic evaluation.

\section{Methods}

PATIENT INCLUSION AND EXCLUSION CRITERIA Eligible patients were men and women less than 76 years of age scheduled to undergo coronary angioplasty and stent implantation; they had stable or unstable angina pectoris or a recent myocardial infarct and no contraindication to inhibition of platelet function with aspirin and ticlopidine or clopidogrel. The protocol required that the patients had a single American College of Cardiology/American Heart Association (ACC/AHA) task force classification type A or B1 non-calcified target lesion, situated in a vessel of $\geqslant 3.0 \mathrm{~mm}$ diameter and free of sharp angulation. Patients scheduled to undergo angioplasty of multiple lesions were eligible for randomisation into the study; however, a single lesion was prospectively included in the analysis, the others being dilated by standard methods, with or without stent implantation. Excluded from the study were patients with acute myocardial infarction or highly unstable angina pectoris refractory to medical treatment, lesions that could not be covered by a single $9 \mathrm{~mm}$ or $16 \mathrm{~mm}$ stent, lesions situated at a bifurcation with a side branch $>2.0 \mathrm{~mm}$ in diameter, left 
main coronary artery lesions, and restenotic lesions.

The study protocol was approved by the ethics review committee of the University Hospital of Rennes, and the study was conducted according to the guidelines listed in the declaration of Helsinki. Written informed consent was obtained from all participating patients.

RANDOMISATION PROCEDURE

Randomisation to stenting without (group I) versus with (group II) balloon predilatation was assigned by telephone communication. To guarantee a balanced randomisation scheme at each enrolling centre, treatments were assigned to each site in blocks of four.

PROCEDURAL PROTOCOL

In the group of patients randomised to stent placement preceded by balloon dilatation (group II), coronary angioplasty was performed by the femoral approach using standard techniques, with a balloon size chosen according to the angiographic arterial diameter. One or more inflations were performed to obtain a visually estimated residual vessel stenosis of $<30 \%$, following which the stent was implanted. Identical techniques were used in group I, except for implantation of the stent without balloon predilatation. Crossover to balloon predilatation was allowed when the stent could not be successfully advanced through the lesion.

In both groups, an inflation pressure of at least $10 \mathrm{~atm}$ was recommended. NIR stents (Medinol, Tel Aviv, Israel) were used in all patients. Stent dimension (9 or $16 \mathrm{~mm}$ ) was chosen according to the length of the stenosis. The stent was premounted on a Viva Primo balloon (Boston-Scimed, Galway, Republic of Ireland), which includes two radio-opaque markers between which the stent was inserted.

\section{INTRAVASCULAR ULTRASOUND STUDY}

In two participating study centres, an intravascular ultrasound (IVUS) substudy, which included 60 patients, was performed with single element $30 \mathrm{MHz}$ transducers rotating at $1800 \mathrm{rpm}$, withdrawn automatically at a speed of $0.5 \mathrm{~mm} / \mathrm{s}$ within a 3.2 French monorail imaging system (Cardiovascular Imaging systems, Sunnyvale, California, USA). IVUS was performed before intervention and after stent placement in the 60 patients, as well as after balloon angioplasty in the 30 patients randomised to predilatation. Complete imaging sequences were obtained-from beyond the lesion, or stent, to the guiding catheter. The images were recorded on high resolution s-VHS tapes for off-line analysis.

\section{ANTITHROMBOTIC REGIMEN}

All patients received aspirin $160 \mathrm{mg} /$ day and ticlopidine $250 \mathrm{mg}$ twice daily, or clopidogrel $75 \mathrm{mg}$ once a day for one month after stent implantation. A single intravenous bolus of 10000 units of heparin was given at the beginning of the procedure.
DEFINITIONS

Procedure time was defined as the time interval between placement of the arterial sheath and removal of the guiding catheter. Immediate angiographic success was defined as stent placement with $<30 \%$ residual stenosis and a normal arterial flow (TIMI (thrombosis in myocardial infarction ) flow grade 3). Primary success was defined as immediate angiographic success without major in-hospital complication, including death, myocardial infarction, stent thrombosis, or emergency coronary artery bypass surgery. Lesions were classified according to the definitions recommended by the ACC/AHA task force. ${ }^{8}$

\section{STUDY END POINTS}

Primary

The primary end point of the study was the immediate angiographic success after proper positioning and deployment of a 9 or $16 \mathrm{~mm}$ NIR stent, according to the procedure assigned by randomisation.

\section{Secondary}

The following variables were measured and compared: fluoroscopy and overall procedure times; amounts of contrast agent given; residual dissections after stenting and need for a second stent; creatine kinase concentrations at 24 hours; and ischaemic event rates at 30 days, including death, myocardial infarction, readmission to hospital for unstable angina, and the need for additional target vessel revascularisation.

\section{QUALITATIVE AND QUANTITATIVE CORONARY} ANGIOGRAPHY AND ANALYSIS

Coronary angiograms were performed before balloon predilatation or stent placement, and immediately after stent placement in all patients. Standard acquisition procedures were followed for qualitative and quantitative coronary angiography analysis. To improve the accuracy and reproducibility of measurements, intracoronary linsidomine $(1 \mathrm{mg})$ or isosorbide dinitrate $(1-3 \mathrm{mg})$ was given before the initial and before the final poststent placement angiograms. Data collection included assessment of TIMI flow grade, lesion eccentricity, estimation of thrombus load, and AHA/ACC classification. An independent laboratory (Lille Core Laboratory, Lille, France) performed routine quantitative coronary angiography measurements with a Medis System (version 3.32.6, MEDIS Medical Imaging Systems, Leiden, Netherlands). Two orthogonal angiographic views which minimised vessel foreshortening were obtained, and the cineangiogram showing the most severe stenosis was selected for quantitative coronary angiography. Postprocedure angiograms, which duplicated the initial orthogonal views, were obtained after the removal of the balloon and guide wire. 
Table 1 Baseline clinical data

\begin{tabular}{llll}
\hline & $\begin{array}{l}\text { Stenting without } \\
\text { predilatation }(n=197)\end{array}$ & $\begin{array}{l}\text { Stenting with predilatation } \\
(n=199)\end{array}$ & $p$ Value \\
\hline Age (years) (mean (SD)) & $59.7(10.6)$ & $60.5(10.9)$ & 0.468 \\
Sex (M/F) & $152(77) / 45(23)$ & $166(83) / 33(17)$ & 0.117 \\
& & & \\
Risk factors & $25(12.7)$ & $27(13.6)$ & 0.796 \\
Diabetes mellitus & $84(42.6)$ & $81(40.7)$ & 0.696 \\
Hypertension & $126(64.0)$ & $131(65.8)$ & 0.697 \\
Hypercholesterolaemia & $52(26.4)$ & $53(26.6)$ & 0.957 \\
Current smoker & $59(30.0)$ & $55(27.6)$ & 0.612 \\
Family history of CAD & & & \\
Clinical presentation & $63(32.0)$ & $74(37.2)$ & 0.276 \\
Stable angina & $78(39.6)$ & $82(41.2)$ & 0.744 \\
Unstable angina & $48(24.4)$ & $49(19.6)$ & 0.252 \\
Recent MI (<1 month) & $8(4.1)$ & & 0.234 \\
Silent ischaemia & & $38(19.1)$ & \\
Coronary history & $37(18.8)$ & $24(12.1)$ & 0.936 \\
Myocardial infarction & $21(10.7)$ & $5(2.5)$ & 0.661 \\
Coronary angioplasty & $6(3.1)$ & & 0.747 \\
Coronary bypass surgery & & & \\
\hline
\end{tabular}

Values are $\mathrm{n}(\%)$ unless stated.

$\mathrm{CAD}$, coronary artery disease; $\mathrm{MI}$, myocardial infarction.

Table 2 Angiographic characteristics

\begin{tabular}{llll}
\hline & $\begin{array}{l}\text { Stenting without } \\
\text { predilatation }\end{array}$ & $\begin{array}{l}\text { Stenting with } \\
\text { predilatation }\end{array}$ & p Value \\
\hline Coronary artery disease (n (\%)) & $119(60.4)$ & $128(64.3)$ & 0.635 \\
$\quad$ One vessel & $61(31.0)$ & $53(26.6)$ & \\
$\quad$ Two vessel & $17(8.6)$ & $18(9.1)$ & \\
Three vessel & $63.3(11.0)$ & $63.6(9.9)$ & 0.769 \\
LVEF (\% (SD)) & $69(35.0)$ & $86(43.2)$ & 0.326 \\
Target vessel (n (\%)) & $50(25.4)$ & $40(20.1)$ & \\
LAD & $76(38.6)$ & $72(36.2)$ & \\
Left circumflex & $2(1.0)$ & $1(0.5)$ & \\
Right coronary & $79(40.1)$ & $93(46.7)$ & \\
Saphenous vein graft & $118(59.9)$ & $106(53.3)$ & \\
ACC/AHA lesion type (n (\%)) & A & & \\
B1 & & & \\
\hline
\end{tabular}

ACC/AHA, American College of Cardiology/American Heart Association; LAD, left anterior descending coronary artery; LVEF, left ventricular ejection fraction.

QUANTITATIVE INTRAVASCULAR ULTRASOUND STUDY

An independent laboratory performed quantitative IVUS measurements (Brest Core Laboratory, Brest, France). Consecutive IVUS images of optimal quality were digitised off-line on a work station Iô3.1 (Iô DP data processing, Paris, France). Using computer planimetry, 18-20 cross sectional areas were measured at $1 \mathrm{~mm}$ intervals. The space encompassing the leading edge between the hypoechoic media and the echoreflective adventitia defined the arterial external elastic membrane area, and the area within the lumen-intima boundary defined the lumen. The lesion site selected for analysis was the image slice with the smallest luminal cross sectional area. Proximal and distal reference segments were identified as the most normal appearing cross sections proximal and distal to the lesion, at least $10 \mathrm{~mm}$ away from any side branch. Plaque area was defined as the difference between the external elastic membrane and luminal cross sectional areas. Measurements made included cross sectional area of the external elastic membrane, lumen, and plaque before and after stent deployment in both groups. These were done by a single investigator (MG). Changes in the analysed areas were calculated as the differences between pre- and postprocedure measurements in groups I and II. The intraclass correlation coefficient was 0.95 for repeated measurements of external elastic membrane cross sectional area and 0.972 for lumen cross sectional area.

PATIENT FOLLOW UP

All major clinical events-including death, myocardial infarction, readmission to hospital for unstable angina pectoris, and the need for additional revascularisation of the target vessel - were monitored by telephone inquiry up to 30 days after the procedure.

STATISTICAL ANALYSIS

The estimate of the sample size was based on the primary end point-angiographic success with respect of the procedure allocated by randomisation. Using a two sided test for differences of independent binomial proportions at a $5 \%$ significance level with a power of $90 \%, 400$ patients (200 in each arm) were required to detect a $5 \%$ difference between the two procedures. Descriptive statistics were performed by group (mean (SD)) for quantitative variables and absolute and relative frequencies for qualitative variables. The variables in the two groups were compared using Student's $t$ test for quantitative variables and the $\chi^{2}$ test or Fisher's exact test for qualitative variables. The $\alpha$ level of significance used was $5 \%$.

\section{Results}

CHARACTERISTICS OF THE PATIENTS

Four hundred patients were randomised between April 1998 and December 1999. Four patients did not undergo percutaneous transluminal coronary angioplasty (PTCA) or withdrew their informed consent. The final study population included 396 patients, 197 randomised to group I and 199 to group II. The patients' baseline clinical and angiographic characteristics are presented in tables 1 and 2. Their mean (SD) age was 60 (10) years, $80 \%$ were men, $40 \%$ had unstable angina, and $62 \%$ had single vessel disease. The left anterior descending and right coronary arteries were the most common target vessels. Stenosis of a vein graft was present in three patients. The two randomised groups were strictly comparable for all baseline clinical and angiographic characteristics.

\section{PROCEDURAL OUTCOMES}

A single NIR stent was implanted in each of the 396 patients. Approximately two thirds of patients received a $16 \mathrm{~mm}$ stent, one third a $9 \mathrm{~mm}$ stent, and a single patient received a $32 \mathrm{~mm}$ stent. The size of the guiding catheter was 6,7 , or 8 French in, respectively, $77 \%$, $15.5 \%$, and $7.5 \%$ of cases (the same proportions in both groups). The mean balloon inflation pressure was 12.14 (2.24) atm (12.44 (2.28) atm in group I $v 11.85$ (2.18) atm in group II (NS)). Stent implantation (9 or $16 \mathrm{~mm}$ NIR stent) was successfully completed without balloon predilatation in 192 of 197 
Table 3 Procedural data

\begin{tabular}{|c|c|c|c|}
\hline & $\begin{array}{l}\text { Stenting without } \\
\text { predilatation }\end{array}$ & $\begin{array}{l}\text { Stenting with } \\
\text { predilatation }\end{array}$ & p Value \\
\hline Stent type & & & 0.062 \\
\hline $\operatorname{NIR}(9 \mathrm{~mm})$ & $68(34.5 \%)$ & $51(25.6 \%)$ & \\
\hline NIR (16 mm) & $129(65.5 \%)$ & $147(73.9 \%)$ & \\
\hline NIR (32 mm) & 0 & $1(0.5 \%)$ & \\
\hline \multicolumn{4}{|l|}{ Duration } \\
\hline Overall procedure (min) & $23.5(13.5)$ & $28.0(15.2)$ & 0.002 \\
\hline Fluoroscopic exposure (min) & $6.0(4.1)$ & $6.7(3.7)$ & 0.114 \\
\hline Contrast agent (ml) & $135.1(65.4)$ & $157.0(62.6)$ & $<0.001$ \\
\hline \multicolumn{4}{|l|}{ Balloon characteristics } \\
\hline Mean diameter $(\mathrm{mm})$ & $3.31(0.34)$ & $3.32(0.33)$ & 0.932 \\
\hline Maximum inflation pressure (atm) & $12.44(2.28)$ & $11.85(2.18)$ & 0.09 \\
\hline Additional inflation after stenting (\%) & $26(13.2)$ & $18(9.1)$ & 0.189 \\
\hline \multicolumn{4}{|l|}{ Results } \\
\hline Angiographic success ${ }^{\star}$ & $192(97.5 \%)$ & $197(99.0 \%)$ & 0.283 \\
\hline Final angiographic success & $197(100 \%)$ & $199(100 \%)$ & \\
\hline
\end{tabular}

Values are mean (SD) or $\mathrm{n}(\%)$.

${ }^{\star}$ According to procedure assigned by randomisation.

Table 4 Quantitative coronary angiography

\begin{tabular}{|c|c|c|c|}
\hline & $\begin{array}{l}\text { Stenting without } \\
\text { predilatation }\end{array}$ & $\begin{array}{l}\text { Stenting with } \\
\text { predilatation }\end{array}$ & $p$ Value \\
\hline Stenosis length (\%) & & & 0.531 \\
\hline$<10 \mathrm{~mm}$ & 93.9 & 92.3 & \\
\hline $10-20 \mathrm{~mm}$ & 6.1 & 7.7 & \\
\hline \multicolumn{4}{|l|}{ Reference diameter (mm) } \\
\hline Before intervention & $3.09(0.45)$ & $3.11(0.41)$ & 0.512 \\
\hline After stenting & $3.19(0.43)$ & $3.18(0.39)$ & 0.826 \\
\hline \multicolumn{4}{|l|}{ Minimum lumen diameter $(\mathrm{mm})$} \\
\hline Before intervention & $1.01(0.37)$ & $1.02(0.38)$ & 0.729 \\
\hline After balloon predilatation & - & $2.03(0.47)$ & \\
\hline After stenting & $2.82(0.43)$ & $2.85(0.43)$ & 0.551 \\
\hline Acute gain & $1.81(0.50)$ & $1.84(0.51)$ & 0.685 \\
\hline \multicolumn{4}{|l|}{ Diameter stenosis (\%) } \\
\hline Before intervention & $67.3(11.1)$ & $67.2(11.9)$ & 0.932 \\
\hline After balloon predilatation & - & $34.8(13.5)$ & \\
\hline After stenting & $11.6(7.2)$ & $10.6(8.0)$ & 0.220 \\
\hline
\end{tabular}

Values are mean (SD) unless stated.

Table 5 Intravascular ultrasound data

\begin{tabular}{llll}
\hline & $\begin{array}{l}\text { Stenting without } \\
\text { predilatation }\end{array}$ & $\begin{array}{l}\text { Stenting with } \\
\text { predilatation }\end{array}$ & p Value \\
\hline EEM-CSA $\left(\mathrm{mm}^{2}\right)$ & $15.4(7.2)$ & $14.8(5.9)$ & 0.72 \\
$\quad$ Before intervention & $17.8(7.0)$ & $18.3(7.4)$ & 0.79 \\
$\quad$ After stenting & $1.8(0.7)$ & $1.7(0.6)$ & 0.85 \\
L-CSA $\left(\mathrm{mm}^{2}\right)$ & $5.4(2.5)$ & $5.5(2.1)$ & 0.88 \\
$\quad$ Before intervention & $13.6(6.8)$ & $13.1(5.8)$ & 0.72 \\
$\quad \begin{array}{l}\text { After stenting } \\
\text { P-CSA }\left(\mathrm{mm}^{2}\right)\end{array}$ & $12.4(5.6)$ & $12.8(6.6)$ & 0.79 \\
$\quad$ Before intervention & & \\
\hline
\end{tabular}

Values are mean (SD).

EEM-CSA, external elastic membrane cross sectional area; L-CSA, lumen cross sectional area; $\mathrm{P}-\mathrm{CSA}$, plaque cross sectional area.

patients in group I (97.5\%), and after balloon predilatation in 197 of 199 patients in group II $(99 \%)(p=0.283)$.

Among the five unsuccessful cases in group I, two could be attributed to inadequate back up with the guiding catheter and three to a distal location of the stenosis in a tortuous vessel. In those five cases, the stent was safely retrieved and successfully implanted after balloon predilatation.

In one patient from group II, balloon angioplasty caused dissection of a length requiring a $32 \mathrm{~mm}$ NIR stent. In one other group II patient, balloon dilatation was preceded by rotablation with a $1.5 \mathrm{~mm}$ burr because of primary failure to cross the lesion with the balloon. In a third group II patient, acute stent occlusion required reopening of the vessel by balloon angioplasty.

Four patients in group II needed an additional stent for a residual dissection and no patient in group I needed this. Angioplasty of another vascular segment was performed in 14 group I patients and eight group II patients, followed by successful stent implantation in 19 patients.

The mean duration of the procedure was significantly longer in group II (27.96 (15.23) mins) than in group I (23.50 (13.54) mins) $(p=0.002)$. Likewise, fluoroscopic exposure was longer in group II (6.67 (3.65) $\min v 6.04$ (4.13) $\mathrm{min}$ ), though the difference was not significant. Finally, the amounts of contrast agent given were 135 (65) $\mathrm{ml}$ in group I versus 157 (62) $\mathrm{ml}$ in group II ( $<<0.001$; table 3$)$.

\section{ANGIOGRAPHIC RESULTS}

The values of the angiographic variables are listed in table 4. No differences were found between the two groups in minimum lumen diameter, per cent stenosis diameter, or reference diameter before angioplasty. The acute gain, minimum lumen diameter, and residual stenosis after stenting were comparable in the two groups.

\section{IVUS RESULTS}

Stent deployment with or without predilatation at identical inflation pressures yielded statistically comparable results in both groups of patients (table 5). The degree of plaque remodelling after coronary stenting with or without predilatation, gauged as the changes in segment dimensions at proximal and distal reference and lesion sites, confirmed that predilatation did not modify the vessel wall response to coronary stenting (table 6).

Table 6 Variations in intravascular ultrasound data with or without predilatation at proximal and distal reference sites and at the lesion site

\begin{tabular}{|c|c|c|c|c|c|c|c|}
\hline \multirow[b]{2}{*}{ Site } & \multirow[b]{2}{*}{$\operatorname{CSA}$} & \multicolumn{2}{|c|}{ Stenting without predilatation } & \multicolumn{2}{|c|}{ Stenting with predilatation } & \multirow[b]{2}{*}{$p$ Value * } & \multirow[b]{2}{*}{$p$ Valuef } \\
\hline & & Baseline $\left(\mathrm{mm}^{2}\right)$ & $V\left(m m^{2}\right)$ & Baseline $\left(\mathrm{mm}^{2}\right)$ & $V\left(m m^{2}\right)$ & & \\
\hline \multirow[t]{3}{*}{ Proximal } & EEM & $15.7(4.5)$ & $0.7(3.2)$ & $17.0(5.2)$ & $-0.9(4.3)$ & 0.09 & 0.31 \\
\hline & $\mathrm{L}$ & $8.3(2.7)$ & $0.2(4.2)$ & $9.0(4.1)$ & $-0.1(2.9)$ & 0.74 & 0.48 \\
\hline & $\mathrm{P}$ & $7.3(3.0)$ & $0.5(4.3)$ & $8.0(5.1)$ & $-0.9(2.6)$ & 0.12 & 0.54 \\
\hline \multirow[t]{3}{*}{ Lesion } & EEM & $15.4(7.2)$ & $-3.7(7.5)$ & $14.8(5.9)$ & $-2.4(6.8)$ & 0.49 & 0.71 \\
\hline & $\mathrm{L}$ & $1.8(0.7)$ & $-3.7(2.1)$ & $1.7(0.6)$ & $-3.6(2.5)$ & 0.85 & 0.85 \\
\hline & $P$ & $13.6(6.8)$ & $0.02(6.9)$ & $13.1(5.8)$ & $-1.2(6.3)$ & 0.50 & 0.72 \\
\hline \multirow[t]{3}{*}{ Distal } & EEM & $11.6(4.2)$ & $-0.6(4.2)$ & $13.5(5.3)$ & $-1.8(4.2)$ & 0.30 & 0.12 \\
\hline & $\mathrm{L}$ & $6.3(2.7)$ & $0.2(3.0)$ & $7.6(3.1)$ & $-1.1(3.2)$ & 0.12 & 0.09 \\
\hline & $\mathrm{P}$ & $5.3(3.1)$ & $-0.18(3.7)$ & $5.9(4.0)$ & $-0.6(3.5)$ & 0.87 & 0.49 \\
\hline
\end{tabular}

Values are mean (SD).

${ }^{\star} \mathrm{p}$ Value between variations; $\dagger \mathrm{p}$ value between baseline data.

EEM, external elastic membrane; L, lumen; P, plaque; V, variation. 
CLINICAL OUTCOMES

In hospital

No death, Q wave myocardial infarction, subacute stent thrombosis, or need for emergency coronary artery bypass graft occurred during hospital admission. Non-Q wave myocardial infarction occurred in two patients in group I $(1 \%)$. The primary success rate according to procedure allocated by randomisation was $96.5 \%$ in group I versus $99 \%$ in group II (NS). Mean creatine kinase enzyme concentrations at 24 hours were 73.8 (80) IU/1 versus 77.7 (58.8) IU/1 (group I $v$ group II; NS). Mean durations of hospital admission were also comparable (2.30 (1.27) days and 2.40 (1.59) days, respectively).

At 30 days

No major cardiovascular event-including death, myocardial infarction, stent thrombosis, or need for additional target vessel revascularisation-occurred within 30 days of follow up. One patient developed ticlopidine induced hepatitis.

\section{Discussion}

This prospective randomised trial confirmed the feasibility and safety of coronary artery stenting without balloon predilatation in simple, non-calcified lesions. Its primary success was high, close to that measured by conventional techniques. This high success rate is concordant with previously published reports and one randomised study of 122 patients. ${ }^{1-7}$ Except for the results of the earliest reportthat of Figulla and colleagues in $1998,{ }^{1}$ where the Palmatz-Schatz stent was used in more than half the patients-angiographic success rates have varied between $93 \%$ and $97 \%$, reaching $100 \%$ after balloon predilatation when the lesion could not be crossed. In the randomised trial reported by Danzi and associates, ${ }^{6}$ and in our present study, the lesions were selected and were mainly of type A or B1 of the ACC/AHA classification. On the other hand, in the other studies, $22-60 \%$ of lesions were of the more complex B2 or C types. However, the lesions were short, with no major angulations proximal to or at the level of dilatation, and without severe calcification. The success rates reported reflect the results of procedures in which these characteristics were present. Thus the patients included in those studies represented only $21-50 \%$ of those undergoing stent implantation during the same period of observation. $^{3-5} 7$

LESION CROSSING FAILURES

In previously published studies, ${ }^{1-7}$ failures to cross the lesions were observed in 44 of 657 attempts $(7 \%)$. Few factors predictive of unsuccessful lesion crossing were identified, owing to the infrequency of failures and the selection of lesions. In the study by Figulla and colleagues, calcifications and older age were more common when the lesion could not be crossed. ${ }^{1}$ On the other hand, the severity of stenosis was not predictive of procedural failure. ${ }^{12}$
In nearly all failed attempts, the stent could be retrieved and reimplanted after balloon dilatation.

INTRAVASCULAR ULTRASOUND STUDY

IVUS is considered the method of choice to confirm satisfactory implantation of coronary stents. ${ }^{9-11}$ Our study is the first to include IVUS data in two comparable groups of patients undergoing stent implantation with or without predilatation. Its main finding was the absence of any difference between the two groups in the degree of lesion dilatation and plaque remodelling. At identical inflation pressures, the results of stent deployment with or without predilatation were comparable. The response of the vessel wall to coronary stenting was independently related to the technique used. In our IVUS study, lumen cross sectional area $\left(\mathrm{mm}^{2}\right)$ after stenting was smaller than reported in the comparable series by Laskey and colleagues $\left(7.2 \mathrm{~mm}^{2}\right)$ and Nakamura and associates $\left(6.9 \mathrm{~mm}^{2}\right),{ }^{11}$ perhaps because of methodological differences among the studies and wide variations in the measurements of the endovascular surface. The obliqueness of the struts and the width of the echo, reflecting the lateral response of the system, complicated the interpretation of the images. In echographic imaging, the struts appear as small segments of a straight line, variably oriented toward the arterial wall. In our measurements, the most endoluminal point of each echo was used as the limit of the lumen cross sectional area.

QUALITY OF STENT IMPLANTATION

The absence of balloon predilatation combined with the use of comparable inflation pressures for placement of the stent may raise concerns about whether the device expanded correctly. However, these concerns are not supported by available angiographic and ultrasound data. In the study by Danzi and colleagues, which included a single angiographic evaluation, stenting with and without predilatation was associated with 7 (4)\% and 7 (5)\% mean residual stenosis, respectively (mean (SD)). ${ }^{6}$ Wilson and associates compared the results of stent implantation in 777 patients with predilatation and in 3176 patients without, and found residual diameter stenosis of 3.7 (11.2)\% and $4.3(10.7) \%$, respectively. ${ }^{7}$

\section{RESIDUAL DISSECTION AFTER STENT}

IMPLANTATION

As observed in our study and by others, ${ }^{7}$ the lack of predilatation of stenosis in direct stenting may decrease the occurrence of residual dissection after stenting and the need for additional stent implantation. The use of stents in bail out situations after dissection has been associated with a worse outcome, supporting the possibility that predilatation may be harmful in a small number of patients.

EVENT RATE AT 30 DAYS

The absence of serious cardiovascular events at 30 days among our patients undergoing direct stenting is in agreement with previous reports 
of comparable rates of major early ischaemic events among patients treated with direct stenting and those receiving stents after balloon predilatation. ${ }^{2-5}$

ADVANTAGES OF DIRECT STENTING

Direct stenting potentially shortens the overall duration of the procedure and fluoroscopic exposure. However, the shortening observed in this study was not significant and was less than that reported by Danzi and colleagues. ${ }^{6}$ In SWIBAP, foregoing balloon predilatation only reduced fluoroscopic exposure on average by 0.7 minutes (a $10 \%$ reduction), as opposed to four minutes in the Italian study (36\% reduction). Direct stenting also reduced the amount of contrast agent given in our study by $14 \%$, and in the Italian study by $20 \%$. Finally, this strategy saves the cost of the balloon used in the predilatation procedure. Danzi and colleagues have estimated a mean saving of $\$ 778$ per procedure, a noteworthy figure if extrapolated to the total number of procedures performed annually. ${ }^{6}$

The additional potential benefit of a reduction in intrastent restenosis has been suggested by the experimental study of Rogers and colleagues. ${ }^{13}$ However, this hypothetical benefit has not been confirmed in any clinical study. In the report by Wilson and associates, one year survival free of major cardiac events (death, myocardial infarction, or need for revascularisation) was strictly comparable among patients who underwent stent implantation with or without balloon predilatation. ${ }^{7}$

Finally, it has been hypothesised that predilatation of unstable plaques in the context of unstable angina or myocardial infarction may facilitate embolisation of cholesterol and necrotic debris and increase the likelihood of no reflow. ${ }^{3}$ Topol and Yadav have recently underscored the importance of embolisation during percutaneous coronary interventions. ${ }^{14}$ In a series of 22 patients undergoing direct stenting during the acute phase of myocardial infarction, no distal embolisation was observed, and TIMI grade 3 flow was re-established in all patients. ${ }^{15}$ However, a significant decrease in distal embolisation and the no reflow phenomenon by direct stenting remains to be confirmed by ongoing large randomised studies of patients with unstable angina or acute myocardial infarction.

LIMITATIONS OF DIRECT STENTING

This therapeutic approach has several limitations. First, the choice of a stent of optimal length and diameter is limited by the absence of previous exposure to a balloon of known dimensions. Second, the stent position may be uncertain if it is occlusive across a tight stenosis, particularly if only $8-9 \mathrm{~mm}$ long, and in absence of any anatomical landmark such as a small collateral vessel. In all cases, the best catheter back up should be in place. Finally, several anatomical presentations are unfavourable, including severe calcification, pronounced vessel angulation, bifurcation lesions, and complete occlusions. Few data are available on ostial or lengthy lesions.

\section{STUDY LIMITATIONS}

The 400 randomised patients - enrolled over a 20 month period in 15 medical centres performing $>400$ coronary angioplasties annually - were highly selected. The results of this analysis cannot, therefore, be immediately extrapolated to the overall population of patients undergoing coronary artery stenting, limiting the accuracy of any cost effectiveness estimates of this strategy.

The IVUS substudy clearly showed an underexpansion of stents in both groups. However, this was only an observational study and not a guided IVUS stent deployment study.

\section{CONCLUSIONS}

Direct stenting of non-complex and noncalcified coronary lesions is feasible and safe. The main advantage of this strategy is economic, saving overall procedural time, contrast agent, and balloons. A hypothetical advantage relating to reduced intimal hyperplasia or intrastent restenosis will only be demonstrable by a detailed angiographic examination at six months, including quantitative measurements of the severity and length of restenosis and a qualitative description of their location (that is, within the stent or elsewhere). The application of direct stenting to more complex lesions should be applied with caution, as it requires a most rigorous scrutiny of this new technique.

We wish to thank Ms Marie Hélène Chevalier and Ms Jeanne Bruner for their help in the development and monitoring of the study.

The following institutions and investigators participated in the SWIBAB trial (the number of patients enrolled at each centre is shown in parentheses): Clinique St Martin, Caen (90): P Commeau, B Huret, J F Morelle; Centre Hospitalier Universitaire, Rennes (71): M Bedossa, C Leclercq, D Boulmier, H Le Breton; Nouvelles Cliniques Nantaises-St Henri, Nantes (50): Breton; Nouvelles Cliniques Nantaises-St Henri, Nantes (50): P Brunel, B Leurent, Y Banus; Centre Hospitalier Universitaire, Brest (44): J Boschat, M Gilard; Clinique du Grand Large, Brest (29): C Breut, E Gestin; Clinique St Gatien, Tours (28): O Bar, A Bonnemazou, D Blanchard; Centre Hospitalier Universitaire, Angers (27): P Geslin, A Furber; Centre Hospitalier Universitaire, Nantes (12): A Tirouvanziam, D Crochet; Centre Hospitalier Universitaire, Tours (11): L Maillard, L Quilliet, B Desveaux, P Raynaud; Clinique La Reine Blanche, Orléans (11): B Moquet; Hôpital Beauregard, Marseille (9): P Barragan; Centre Hospitalier Universitaire, AP-HP, Créteil (7): P Dupouy, J L Dubois-Randé; Centre Hospitalier Universitaire, Caen (5): G Grollier, M Hamon; Clinique St Hilaire, Rouen (3): J Berland; Clinique St Laurent, Rennes (2): P Druelles, Y Biron, C Descaves, C Pico-Bourdonnec; Centre Hospitalier St Philibert, Lomme (1): R Rihani.

1 Figulla HR, Mudra H, Reifart N, et al. Direct coronary stenting without predilatation: a new therapeutic approach with a special balloon catheter design. Cathet Cardiovasc with a special balloon

2 Pentousis D, GuérinY, Funck F, et al. Direct stent implantation without predilatation using the MultiLink stent. Am $\mathcal{F}$ Cardiol 1998;82:1437-40

3 Hamon M, Richardeau Y, Lécluse E, et al. Direct coronary stenting without balloon predilation in acute coronary syndromes. Am Heart $\mathcal{F}$ 1999;138:55-9.

4 Herz I, Assali A, Solodky A, et al. Effectiveness of coronary stent deployment without predilation. Am $\mathcal{f}$ Cardiol 1999;84:89-91.

5 Briguori C, Sheiban I, De Gregorio J, et al. Direct coronary stenting without predilation. F Am Coll Cardiol 1999;34: 1910-15.

6 Danzi GB, Capuano C, Fiocca L, et al. Stent implantation without predilation in patients with a single, non calcified coronary artery lesion. Am f Cardiol 1999;84:1250-3. 
7 Wilson SH, Berger PB, Mathew V, et al. Immediate and late outcomes after direct stent implantation without balloon predilation. $\mathcal{F}$ Am Coll Cardiol 2000;35:937-43.

8 Ryan TJ, Faxon DP, Gunnar RM, et al. Guidelines for percutaneous transluminal coronary angioplasty. A report of the American College of Cardiology/American Hear Association task force on assessment of diagnostic and therapeutic cardiovascular procedures (subcommittee on percutaneous transluminal coronary angioplasty). Circulation 1988;78:486-502

9 Gorge G, Haude M, Ge J, et al. Intravascular ultrasound after low and high inflation pressure coronary artery stent implantation. 7 Am Coll Cardiol 1995;26:725-30.

10 Goldberg SL, Colombo A, Nakamura S, et al. Benefit of ultracoronary ultrasound in the deployment of PalmazSchatz stents. F Am Coll Cardiol 1994;24:996-1003.
11 Nakamura S, Colombo A, Gaglione A, et al. Intracoronary ultrasound observations during stent implantation. Circulation 1994;89:2026-34.

12 Laskey WK, Brady ST, Kussmaul WG, et al. Intravascular ultrasonographic assessment of the results of coronary artery stenting. Am Heart f 1993;125:1576-83.

13 Rogers C, Parikh S, Seifert P, et al. Endogenous cell seeding. Remnant endothelium after stenting enhances vascular repair. Circulation 1996;94:2909-14.

14 Topol EJ, Yadav JS. Recognition of the importance of embolization in atherosclerotic vascular disease. Circulation 2000;101:570-80.

15 Herz I, Assali A, Solodky A, et al. Coronary stent deployment without predilation in acute myocardial infarction: a feasible, safe and effective technique. Angiology 1999;50:901-8.

\section{IMAGES IN CARDIOLOGY}

\section{Systemic sclerosis involving the heart}

A 39 year old woman with systemic sclerosis (scleroderma) presented with four months ofdyspnoea. Initial investigation including coronary angiography, echocardiography, and cardiovascular magnetic resonance (CMR) without contrast were normal. Over three months she became more breathless and developed arrhythmias. CMR was repeated with contrast. The right ventricle was now dilated
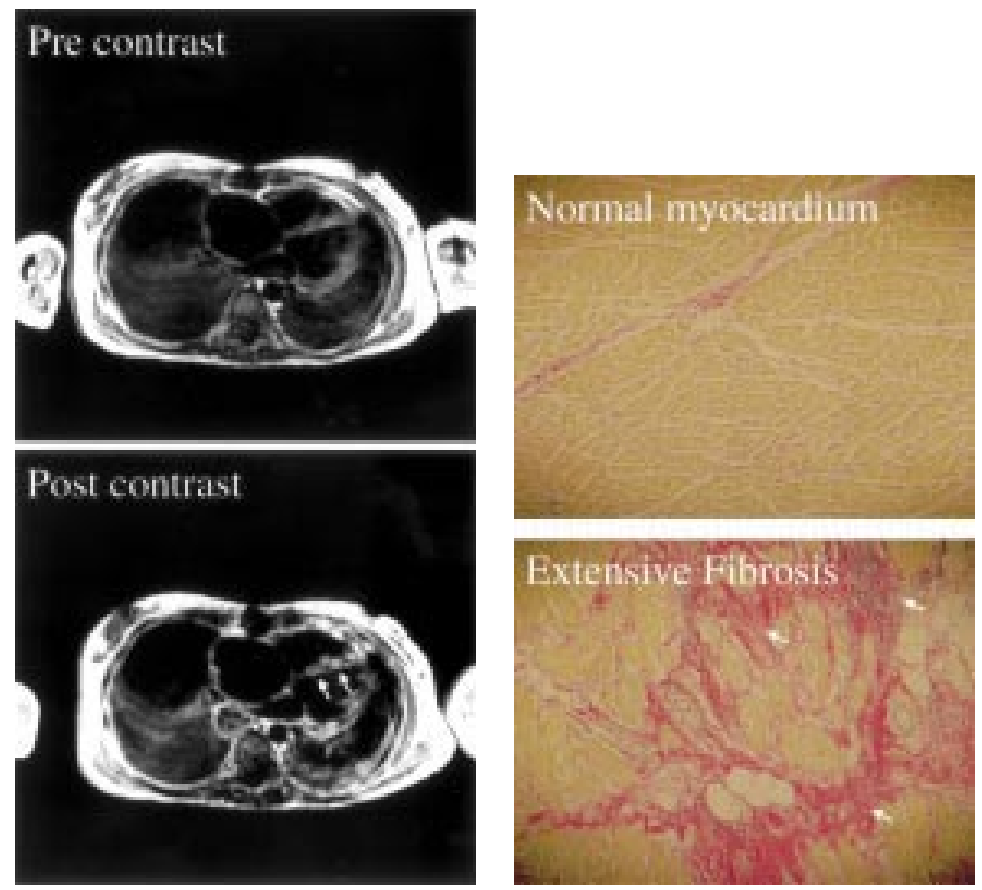

with poor function. There was reduced left ventricular function and bilateral pleural effusions were present. The myocardium enhanced greatly with gadolinium at 20 minutes in a heterogeneous pattern, suggesting a patchy process such as fibrosis or infiltration (below left). One month later, despite treatment, the patient entered a terminal low output state with malignant arrhythmias. At postmortem examination the myocardium was grossly abnormal. Large islands of normal myocardium were interspersed with areas of myocardial oedema with myocyte loss, while other areas showed extensive sheets of fibrosis (below right).

Systemic sclerosis is an uncommon cause of cardiomyopathy, although cardiac involvement in systemic sclerosis may be under recognised clinically. Vasospasm and fibrosis occur throughout the body and in the heart this may result in patchy perfusion defects, diastolic dysfunction, arrhythmias, and systolic cardiac failure. In this case, heterogeneous myocardial gadolinium contrast enhancement correlated with postmortem findings of patchy myocardial oedema and fibrosis with interspersed normal myocardium. Late contrast enhancement with gadolinium is known to characterise fibrosis and necrosis in myocardial infarction and ischaemic cardiomyopathy. These images show the potential of the technique in other cardiomyopathies and for the assessment of cardiac systemic sclerosis.

JAMES MOON JOHN G COGHLAN DUDLEY J PENNELL jccmoon@rbh.nthames.nhs.uk 